Lee, T. Y. E. (2018). Communicative functions and characterization in the Chinese graphic novel adaptation of Little Women. Linguistica Antverpiensia, New Series: Themes in Translation Studies, 17, 58-70.

\title{
Communicative functions and characterization in the Chinese graphic novel adaptations of Little Women
}

\author{
Tzu-yi Elaine Lee \\ Chung Yuan Christian University, Taiwan \\ bluestone1207@gmail.com
}

This article attempts to use an integrated theoretical framework to examine the three graphic novels published in Taiwan based on Louisa May Alcott's Little Women. After the concept of intertextuality (Kristeva, 1980), Kress and Van Leeuwen's (1996) visual grammar helps us to explore how the visual semiotic resources in three Taiwanese graphic novel editions of Little Women ascribe meanings, achieve functions and communicate ideologies to enhance the characterization of Jo March. Progressing from the images, image-text relationships are discussed in terms of how these signifiers shape signs and meaning. Finally, by exploring speech or thought representation, the researcher investigates the translators' awareness of the readers and situates their use of signs socially and culturally. In this study, the integrated framework reveals how these semiotic resources characterize Jo March, and the double meanings (Kristeva, 1980, pp. 65-66) they present, differently. These characterisations may, in turn, have affected the communicative function of each version. The study concludes with a discussion of the strengths and weaknesses of these applications.

Keywords: Chinese graphic novels, Little Women, intertextuality, visual grammar, speech or thought representation

\section{Introduction}

According to Tabachnick (2017, p. 26), the graphic novel is an extended comic book without restrictions on its form and content. A graphic novel is capable of presenting all the issues that are routinely dealt with in writing and art for adults, using all available literary and artistic resources. This genre evolved from wordless works to the first important graphic novel with both words and pictures (A Contract with God and Other Tenement Stories) in 1978 (Tabachnick, 2017, p. 37). However, the latter form is clearly based on the techniques of comics and uses both words and pictures to create meaning. Rather than the simplified content and limited number of standardized panels contained in comics, the graphic novel can be regarded as an attempt to allow the physical book to survive in an electronic era by combining the advantages of the traditional reading experience with those of the computer screen, which often provides visual objects alongside text (Tabachnick \& Saltzman, 2015, p. 5) and allows readers to linger over a given passage or look backwards or forwards without any constraints or time pressure (Tabachnick \& Saltzman, 2015, p. 10). According to Gardner and Herman (2011, p. 1), the significance of the graphic novel lies in its importance as a storytelling medium, which serves as "the message" (McLuhan, 1964, p. 24) and establishes communication between the adapted text and the reader, in this way facilitating the reader's understanding of both texts.

Scholarship on graphic novel adaptation has taken various directions, although most studies have focused on pedagogy in higher education (e.g., Carter, 2017, pp. 192-209; Tabachnick, 2009, pp. 58-68; Tondro, 2015, pp. 33-45). Discussions of graphic novels in Translation Studies are rare, although related pioneering research on multimodality has 
appeared in recent years, as in studies by Oittinen (2000), Kaindl (2004) and Ketola (2016). Although scholars such as O’Sullivan (2013), Kaindl (2013) and González (2014) have called for more investigative instruments to be developed for analysing multimodal texts, more benefit can be gained by approaching such texts from different angles. This is an important motive for the present article.

In this study, the adapted text under examination is Little Women. The author, Louisa May Alcott, was born in 1832 in Concord, Massachusetts. Her adolescence coincided with the formative years of the women's movement in the 19th century, which sought to liberate women from the increasingly rigid roles of rearing children, supervising servants and creating a domestic haven for men (Keyser, 2000, p. 6). Moreover, literary works and conventions produced by feminists such as Margaret Fuller and Elizabeth Stanton in the Transcendentalist circle, to which Alcott's father belonged, laid the foundation for and justified Alcott's craving for individuality, independence and achievement. As such, Little Women can be seen as a transitional book in 19th-century America (ibid., p. 11) and was a huge success (Showalter, 1991, p. 53), especially because none of its predecessors was intended specifically for children. In addition, Little Women became the progenitor of a long list of descendants marketed for children and young adults, including Anne of Green Gables.

Regarded as an important feminist critique of the Transcendentalist movement (Showalter, p. 43), Little Women's major contribution is its reflection of Alcott's liveliness, humour and restrained preachiness (Keyser, 2000, p. 14). In addition, Little Women has survived many changes in literary fashion due to its stress on the peculiar limitations and contingencies of women's experiences in 19th-century America (Gannon, 1999, p. 103). Besides its use of the allegorical Pilgrim's Progress by John Bunyan (1678) as its spiritual and moral framework, numerous examples of games, theatrical performances, parties and entertainment abound in the story. Much of this vitality is attributed to the heroine, Jo March, whose vocation and individual quest in combination with societal forces inside and outside of the family present her as a contradictory figure, a being of domesticity and subversion.

The novel has inspired three graphic novel versions in Taiwan to date: Kurasawa and Xiao's Little Women (2003), Kim and Kim's Little Women (2006) and Nev and Huang's Little Women (2013), each with different pairs of illustrators and translators. Each version presumably targets different readerships. A personal communication with Book Public Publishing (November 2017) confirmed that the latest adaptation was actually first published in Japan and that the Taiwanese publisher replaced all the Japanese text with Chinese translations. Although there were difficulties in contacting the other two publishers, it is assumed that the 2003 and 2006 versions were potentially imported from Japan and Korea because the translator of the 2006 version, Kim, is Korean, but knows Chinese well.

Through focusing on Jo's development towards independence and womanhood, this study illustrates the lives of the poor but genteel March family, which consists of four sisters and their mother, with their father away fighting in the American Civil War. In the story, the protagonist, Jo March, who is the second daughter, works outside of the home for money to support the family. Jo looks and acts like a tomboy and is impulsive and quick to anger, which creates challenges in life. She becomes good friends with the boy next door, Laurie. In one incident, she refuses to take her sister Amy to the theatre when invited by Laurie. When Jo returns, she is angry to find that Amy has burned her valuable manuscript. Days later, Jo goes ice-skating with Laurie and ignores Amy on purpose; as a result, Amy falls into the frozen lake and nearly dies. Jo feels very remorseful, and the two sisters make their peace again. Later, Jo has success earning money with her writing, which is published in the local newspaper. Suddenly, a telegram arrives with the message that their father is sick, which shocks the family. Owing to the poverty of the family, Jo sells her hair for 25 dollars to pay for her mother's journey to her husband. In the meantime, Meg develops an affection for Laurie's tutor, John Brooke, which makes Jo rather anxious. The story ends positively with their father returning home for Christmas. 
Since the three graphic novels were adapted and translated into Chinese, the interconnectedness of the translation and the adaptation must be considered, as widely discussed in Raw (2013). Although adaptation studies have been regarded as a poor relation and subordinate to translation studies by scholars such as Gambier (1992), Gentzler (1993) and Venuti (2007), this study follows the ideas proposed by VandalSirois and Bastin (2013, pp. 22-25). These latter authors suggest that adaptation can be a tactical method for addressing the linguistic problems in the original text or as a strategic approach to ensuring the relevance and usefulness of the translation. The latter scenario corresponds to the materials the researcher is examining in this study, since the adaptation of the novel Little Women is contingent on communicative need and functionality.

\section{An integrated theoretical framework}

To evaluate multimodal texts from a new and different perspective, the current article attempts an innovative approach to the three graphic novel adaptations of Little Women through the concept of intertextuality. Inspired by and adopted from Mikhail Bakhtin's concept of dialogism, Kristeva believes that a text is constructed out of existing discourse. According to her perspective, authors do not create their texts out of originality, but rather compile them from existing texts. Hence, a text is a constant rearrangement of preexisting texts and is "an intertextuality in the space of a given text", in which "several utterances, taken from other texts, intersect and neutralize one another" (Kristeva, 1980, p. 36). In this sense, a text is not an isolated object and cannot be separated from the larger cultural or social textuality out of which it is constructed (Allen, 2000, p. 35). Such a text, according to Kristeva, is composed of the dynamic "literary word", which serves as an intersection of textuality and as a dialogue between several elements: the writer, the addressee, the character and the contemporary or earlier cultural context (Kristeva, 1980, p. 65). She further defines the dynamic literary word in terms of the horizontal and vertical dimensions of the text: the horizontal dimension belongs to both the writing subject and its addressee, whereas the vertical dimension of the text is oriented towards an anterior or synchronic literary corpus (Kristeva, p. 66). To study intertextuality, according to Kristeva's semiotic approach, is to study the text as a textual arrangement of elements that possess a double meaning - one in the text itself and the other in what she calls "the historical and social text". In this study, Kristeva's concept of intertextuality is applied as a major concept with which to examine different semiotic resources in the three Chinese graphic novels of Little Women in order to understand what the translatorillustrator pairs are trying to communicate to readers on the horizontal axis and how these meanings were or are contextualized in the target culture (TC) along the vertical axis.

Kress and Van Leeuwen (1996) provide a useful visual grammar for analysing the double meanings of semiotic resources, helping the researcher locate and identify the potential meaning of specific signs that belong to a culture and society. This is best integrated with the concept of intertextuality illustrated above to interpret not only how the communicative functions of these visual and verbal signs are selected in each adaptation but also how visual and verbal signs are historically and culturally situated in the target society (Jewitt, 2009, pp. 28-29). Moreover, it describes contemporary visual design and the explicit and implicit knowledge around a social resource in visual communication. Though mainly used for "Western" semiotic modes, it nevertheless provides a solid foundation on which to discuss the visual narratives in the three adaptations of Little Women published in Taiwan, with a specific spotlight on Jo March. Therefore, it becomes possible for the researcher to explore how the visual and verbal resources originally selected in Japan and Korea have been contextualized and adapted for the intended readers of graphic novels in Taiwan and how they relate to the characterization of Jo March. 
In addition, several scholars have examined image-text relationships from different perspectives (Barthes, 1977; Groensteen, 2007; McCloud, 1993; Mitchell, 1986; Postema, 2013). The image-text relationships in these three graphic novels as related to the concept of intertextuality are discussed in this study. Image and text ideally have an interdependent relationship, each extending the meaning of the other in a process described by Barthes $(1977$, p. 39) as a "relay", or with only the one elaborating on the other. For the former "relay", new and different messages are added to complete the message, although this is rarely seen. There are two types of elaboration: that where the verbal text comes first so that the image supplements the message; and that where the image comes first so that the text provides a more definite and precise restatement of what is portrayed. Whether the image or text comes first in any given panel has social control (Kress \& Van Leeuwen, 1996, p. 28) and communicative functions. Although some researchers insist that the visual component of a text is an independently structured message (e.g., Kress \& Van Leeuwen, p. 18), Eisner (1985, p. 110) contends that the image conveys most of the message. Unsworth and Cléirigh (2009, pp. 151-163) suggest a synergistic model of image-text relationships and propose three types of intermodal identification that use images as a departure point:

- $\quad$ an intensive type, with the image visualizing the identified participant;

- a possessive type, with the image visualizing additional participant(s) not explicit in the language, and

- a circumstantial type, with the image visualizing the locations of the language elements.

This synergistic model could be useful in explaining the image-text relationships in the three graphic novels in this study. In contrast, Groensteen $(2007$, p. 129) believes that words can reduce the polysemy within images and therefore anchor them.

Finally, the dialogic relationship between the interpretive choices made by graphic novel adapters and artists (Hutcheon, 2013, p. 2) can be examined effectively through speech-thought representation, since the narrator's interference is mostly present in direct speech (DS) and direct thought (DT; Leech \& Short, 1982, p. 318; Toolan, 1988, p. 120). DS reports exactly what one says by quoting the words verbatim, as in the case of balloons in comics. Likewise, DTs can be presented in thought balloons that provide the characters' inner thoughts. In graphic novels, both speech and thought balloons can contain pictorial and symbolic images. If the speech and thoughts of a character are presented directly, the author means to invite all their readers to see things from the character's perspective (Leech \& Short, 1982, p. 338) and, potentially, to feel the narrator's presence. In addition, this provides a freer form (free DS) that removes the inverted commas, the introductory reporting clause, or both. The use of this presentation form creates the effect that the characters are apparently addressing us more immediately, without a narrator as an intermediary (Leech \& Short, pp. 322-323). The same approach can be applied to free DT. Similarly, as a writer moves along the continuum towards the "freer" end of thought representation, they seemingly give the reader the "verbatim" thoughts of the characters with less interference on their part.

To summarize, in this study, the aim to use the concept of intertextuality, visual grammar, the synergistic model (Unsworth \& Cléirigh 2009, pp. 151-163), and speechthought representation to examine the three graphic novels by progressing from images to image-text relationships and then to text separately.

\section{Three graphic novel adaptations of Little Women}

In this section, the graphic narratives, as defined by Eisner (1996, p. 6), of the three graphic novel adaptations of Little Women are analysed to reveal how they create meaning in text and in society to transmit ideas, particularly regarding the characterization of Jo 
March. Of the three recent graphic adaptations, Nev's (2013) Little Women provides the most detailed and thorough narrative. This adaptation encompasses almost all of the chapters of Book I, including the play and the concept of The Pilgrim's Progress, which are absent from the other two adaptations. Moreover, only the 2006 version is in full colour, in contrast to the otherwise monotonous black and white of the 2003 version and the latest version, which was drawn using a scale of green ranging from maximally light (white) to maximally dark (green), which may be a product of cost concerns. However, the use of the colour green may calm the reader to some extent and achieve a more personal look and feel. According to the concept of intertextuality, the semiotic resources of each of the three graphic novels should be examined from both their horizontal and their vertical dimensions (Kristeva, 1980). Therefore, the semiotic resources selected are discussed in terms of the meaning they present in the story and the way in which they are contextualized in the TC (i.e., Taiwan) and the communicative functions they achieve in these adaptations. In what follows, these three adaptations allow us to observe a progression in the portrayal of character from 2003 to 2013.

\subsection{Image}

This section starts with a visual analysis of the two covers of the adaptations from 2003 (left) and 2006 (right) in Figure 1. Both covers clearly attempt to present the scene in which Mrs March is with her four daughters, implicitly promoting the importance of the family, especially for first-time readers or for those not blessed with a strong visual imagination. However, this scene is represented differently on each cover. In terms of distance, the drawing on the left is mostly at eye level, indicating a medium shot taken approximately at waist level, and the relationship between the represented participants and the viewer is neither too close nor too distant (Kress \& Van Leeuwen, 1996, p. 124). This is how one commonly sees people in social settings and may be used to represent commonplace interactions (Duncan \& Smith 2017, p. 12). Since the four March daughters in the drawing are looking out of frame at something the viewer cannot see, the representation can be regarded as a "non-transactive reaction", which indicates that there is not a specific purpose behind the action. On the contrary, there is a "transactive reaction" on the part of Mrs March, who is smiling at her daughters, especially since the subject of Mrs March's gaze is Jo (Kress \& Van Leeuwen, 1996, p. 175), showing her support and care.

According to the given or new information in the image, as proposed by Kress and Van Leeuwen (1996, pp. 179-185), however, the Japanese adaptation will be read from right to left (the opposite direction to the Western style); hence, the new information should be placed on the very left, an arrangement which may mislead readers to think that Mrs March, who is positioned on the far left, is the protagonist. 


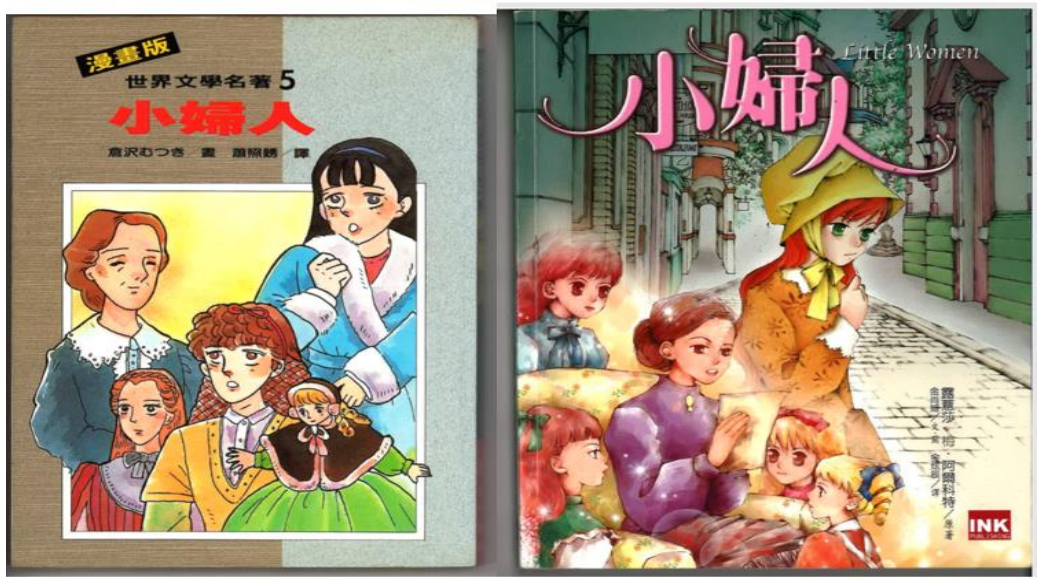

Figure 1: The front covers of the 2003 and 2006 adaptations of Little Women

On the other hand, the Korean adaptation, which is found on the right of Figure 1, has attempted to portray the most iconic representation of the relational bonds (Gannon, 1999 , p. 105) between the March family members in the left corner, which is an improvement over the previous version and faithfully follows the source as the given information. Most importantly, because the Korean version is read from left to right, presenting Jo March at the centre using a fairly long shot makes sense (Duncan \& Smith, 2017 , p. 13) because it highlights her role as the main character. But Jo cannot be identified easily in the family scene in the corner, since the illustrator, Kim, seems to have changed Jo's eye colour arbitrarily. Similar confusion resulting from colour changes is frequently seen in this version, such as when the illustrator changes the colour of Jo's hair and clothes in the close-up shot of the instance in which Jo finds Amy in the icy water, as shown in Figure 2. This change suggests that Kim may have assumed that her readers were familiar with the story before reading it. Alternatively, this change could be an example of her idiosyncratic style. Either way, though her target readers would probably be slightly older rather than younger children, the changes of eye and clothes colours complicate the story.

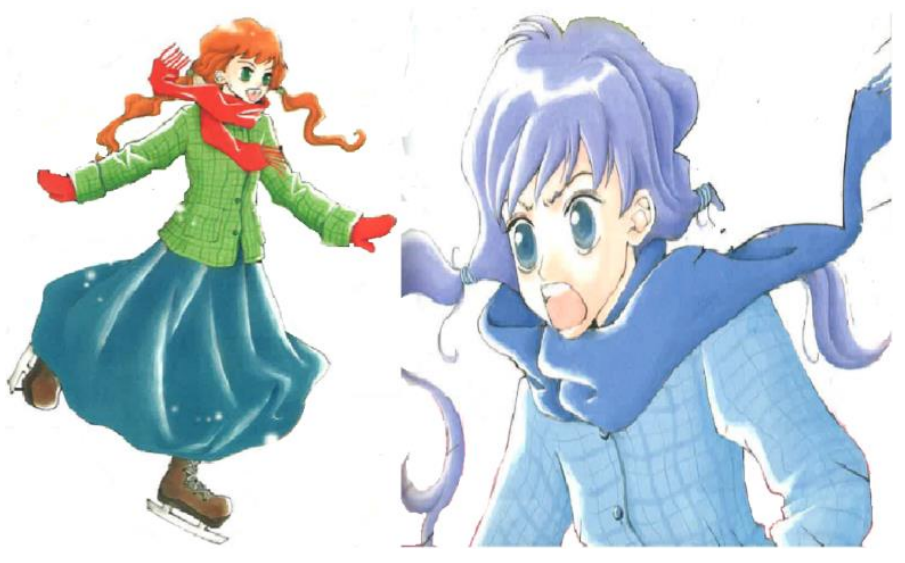

colour in Kim's adaptation

Figure 2: Changes in Jo's hair 
In addition, both adaptations exclude Bunyan's allegorical story and Jo's talents at playwriting, which greatly prefigure Jo's development into maturity and her later success in writing.

Both versions portray Jo visually in somewhat similar ways. Regarding their similarities, both earlier versions frequently change her portrayal, presenting her realistically in major scenes and in cute postures in minor incidents. It seems that Kim's characters are much "cuter" and were probably designed for young readers, as illustrated in Figure 3. The interchangeable presentations not only catch the readers' attention but also facilitate comical effects by eliminating the distance between Taiwanese readers and the character. The Japanese illustrator Kurasawa particularly highlights Jo's curly hair falling over her forehead, which makes it is easy for readers to distinguish her from the other characters. Nevertheless, a comparison of Jo in these two versions reveals that she is much more mature and lady-like in Kurasawa's adaptation than the more child-like Jo in Kim's. In this way, Kurasawa's Jo downplays her mischievous, endearing characteristics, whereas Kim's may attract young readers who are fond of characters with cute appearances, which is a type of social control by the storyteller (Eisner, 1996, p. 50).
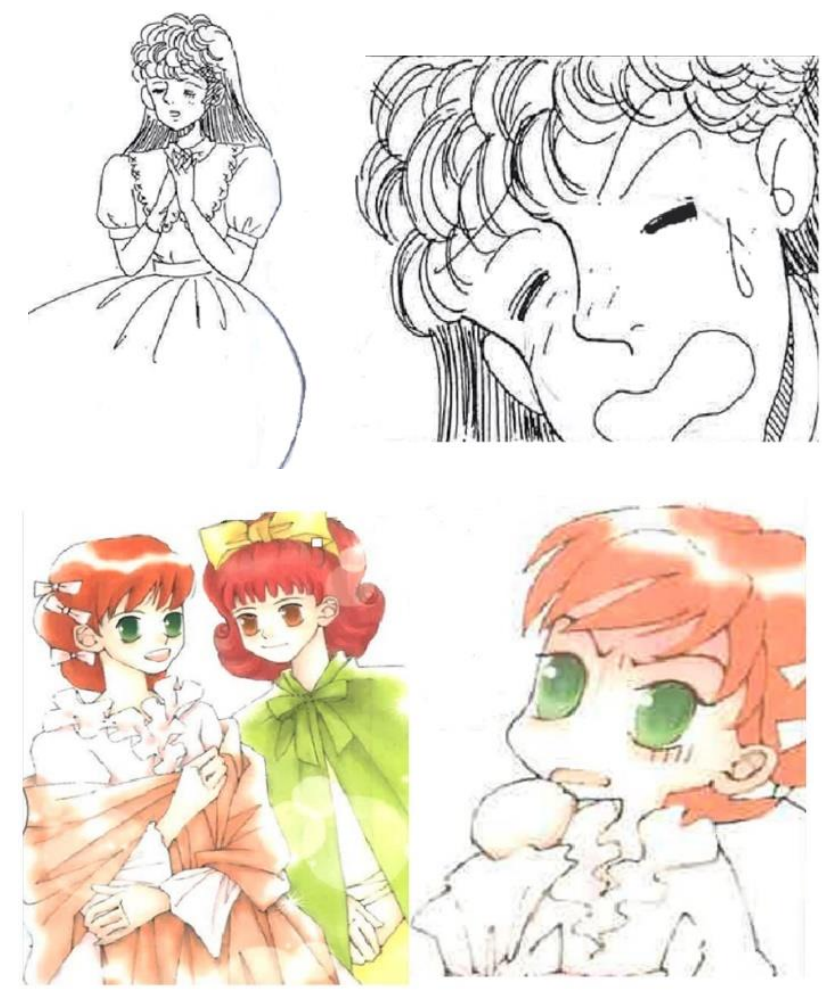

Figure 3: Realistic Jo in Kurasawa's (top) and cute Jo in Kim's (bottom) portrayal

In contrast, the latest adaptation of Little Women discards the iconic presentation of the family scene and uses Jo March positioned as the focal point with a medium shot approximately at her waist level, which is somewhat similar to Kim's portrayal in Figure 4. 


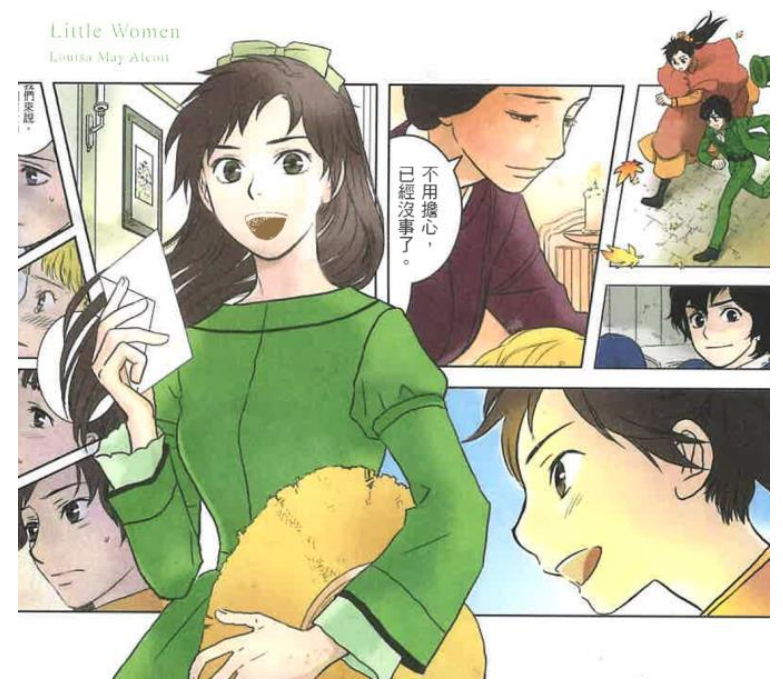

Figure 4: Front cover of the latest adaptation in Taiwan

However, this presentation is much more pleasing because Jo is placed slightly off-centre (Duncan \& Smith, 2017, p. 13). Nev's Jo shows a confident teenager who is ready to take on challenges: her independence and self-assurance are prominent. In addition, Jo looks at her readers directly, as if she wishes to "demand" something from them (Kress \& Van Leeuwen, 1996, pp. 114-153), which also contributes to the cover's communicative function. In other words, Nev's portrayal of Jo makes eye contact with the viewer and, as a result, contact is established.

In addition to the specific characterization in each adaptation, these three portrayals of Jo March can be discussed according to the vertical dimension, according to Kristeva's (1980) intertextuality, regarding how her portrayal has progressed from that of a restrained, lady-like woman to a lovely but mischievous girl, and then to a brave, independent lady with happiness portrayed on her face. From these different portrayals, it is possible to infer that the three illustrators have attempted to construct Jo from their own perceptions of her; even so, these interpretations coincidently correspond to the changing perceptions of women in modern societies. Indeed, these progressive changes in characterizing Jo may have been the main reason that these graphic novels were chosen to be translated and published in Taiwan.

To return to the latest adaptation (Figure 4), in the background, several panels from the story serve as a reminder of the graphic novel format. Indeed, the panels in the latest version are much smaller and more numerous, placed as they are on a single page, whereas the "splash" which uses the entire page as a single panel (Duncan \& Smith 2017, p. 17) or creates a double-page spread (Groensteen, 2007, p. 91), appears frequently in the 2003 and 2006 versions, with dramatic effects. In addition, the latest version is much thicker - nearly 100 pages more than the previous two - suggesting that there is a much more detailed story to be covered. This version may therefore be targeted primarily at those wishing to absorb the whole story as closely to the original as possible, such as adults and professional readers.

\subsection{Image-text relationships}

In this section, the text used outside the speech-thought bubbles is analysed to consider how this text uses the images and contributes to meaning-making. The following examples indicate that the potential relationships actually originate from the collaboration 
of the illustrator and the translator, who work together to enrich the interpretation process (Tabachnick \& Saltzman, 2015, p. 3).

The three adaptations share similarities in that the translators or the illustrators have taken liberties in using onomatopoeia with different fonts and larger sizes, mostly to convey the characters' actions and emotions and the sounds or noises in the environment to present their ideational function to the readers. This is done in contrast to the "emanata" that usually appear in comic arts (Duncan \& Smith, 2017, p. 14), the set of symbols used to reveal the inner states of the characters, such as a floating heart over a newly wed couple to indicate that they are in love or motion lines to highlight the direction in which the character is running. In our three texts, the application of visual sounds can be viewed as an attempt to heighten the realism of the characters' experience. Such usage helps to elaborate the image (Barthes, 1977, p. 39) by highlighting the characters' physical movements and sounds, in that way contributing to circumstantial identification, according to Unsworth and Cléirigh (2009, pp. 151-163) - although in this case the onomatopoeia glosses the image. Of the three versions, onomatopoeia is most frequently used in Kim's, especially when the cute form of Jo March appears, which contributes to her representation Taiwanese readers as a lively, optimistic and open-minded girl, with potential targeting of Taiwanese readers who favour comic effects more.

In addition, the text outside of the speech bubbles of supporting characters is

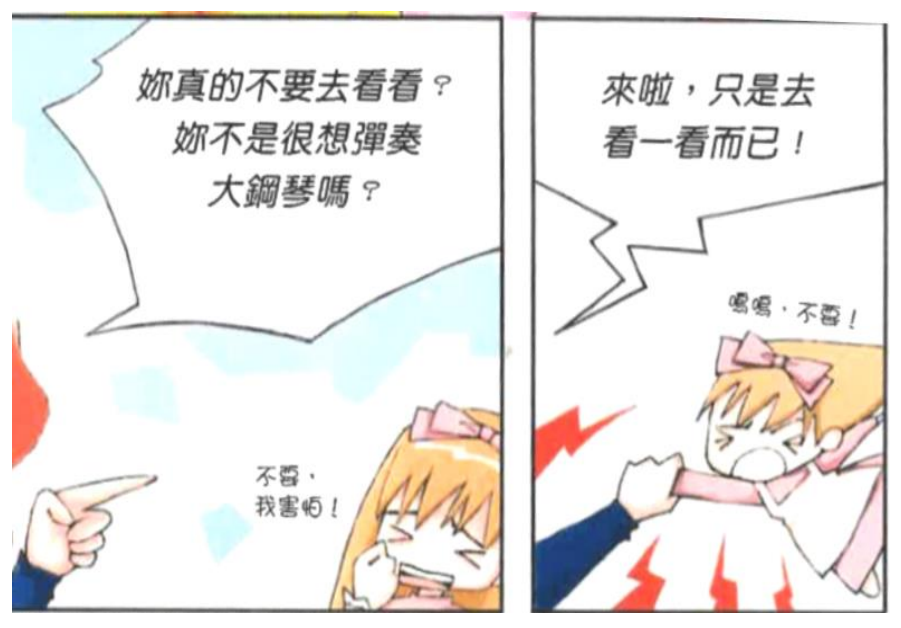
commonly seen in Kim's adaptation, mostly in the form of a short phrase or a few words that convey meaning that is lacking in the speech bubbles, as shown in Figure 5.

Figure 5: Texts outside speech bubbles in Kim's adaptation

Although Barthes (1977, p. 39) believed that this form of representation, or "relay", is rarely seen, one example has been found in this study that especially enhances the readers' understanding, supplements interest and communicates with the readers. Moreover, the words of a narrator or a character off-panel are superimposed over the panel to explain or create an effect. This can be regarded as a form of possessive identification, such as that in the note explaining "scarlet fever" in Kurasawa and Kim's versions. That note, along with the possible medical treatment, suggests the concept of a "thick translation" as introduced by Appiah (2000), who draws upon Clifford Geertz's ethnographic experience of a "thick description". In this fashion, it can be inferred that 
the narrator or the translator means to explain the term to young readers . In this way, the notes also serve a communicative function. Interestingly, only Nev's latest version does not provide any note for the term "scarlet fever", which could echo the previous assumption that this version is actually aimed at adults or even professional readers.

\subsection{Speech and thought representation}

In this section, the speech and thought representation is analysed to determine how the translators (Xiao, Kim and Huang) achieved the communicative function in their adaptations. Since DS and DT are the most common types of speech and thought representations in graphic novels (Tang, 2016), these are investigated first to see if they create double meanings in any of the three adaptations (Kristeva, 1980, pp. 65-66); it would also be useful to determine whether the narrator or the translator interferes with Jo March's speech and thought balloons. Indeed, comics can also make us privy to the inner thoughts of characters through thought balloons. These thoughts are usually depicted in scalloped balloons connected to their thinker with a trail of cloud-like puffs (Eisner, 1996, p. 26).

Regarding the speech and thought representations in the three adaptations, the following can be stated. The size of the Chinese characters in the speech or thought balloon in the translator Xiao's version must be noted because it changes at random. The possible reason for such changes could be the differences between languages; in this instance, for example, the Japanese text in the original and the Chinese in the translation could not fit into the original bubble exactly. Therefore, the publisher may have decided to increase or decrease the size of the Chinese characters. In this way, the changing sizes of the Chinese characters in the speech bubbles may not merely look strange, but could also constantly reminds readers that the adaptation is a translation. Moreover, some "Japanese usage" appears in Xiao's version : in a scene when Amy wishes to follow Meg and Jo to the theatre but Jo refuses to let her, Amy says, “我不會給羅萊添麻煩的”, which can be back-translated as, "I won't burden Laurie with troubles!" At first glance, this sentence seems fine, yet such an expression does carry a double meaning. It can simultaneously refer to Amy's promise to not burden Laurie with trouble in the text; but it can also suggest the usage "burden troubles", which is characteristic of Japanese manners, emphasizing "not to trouble others". It would seem that the translator, Xiao, was influenced by the original language, Japanese. And it could also be inferred that the translator or the publisher may have assumed that such a usage would be accepted by the target readers. It makes sense for the publisher to believe so, as Taiwan has long been under the influence of Japan in the areas of language usage and culture.

Finally, every character in Xiao's translation has been marked with phonetic symbols that clearly target younger readers in Taiwan, possibly first- and second-graders.

An examination of the speech and thought balloons in the three adaptations reveals that translator interference is manifested in speech balloons mostly to highlight the name of the actor instead of using "you" (i.e., explaining that Jo, Meg and Laurie are going to a play) or to provide an explicit explanation to Taiwanese readers for the "American dollars" that Jo earns by selling her hair). Such interference in these three adaptations may, to some extent, help with in understanding or even enhance the communication between the translators and their readers. But it may also run the risk of presenting an unnatural story or even de-contextualizing a specific scene.

Interestingly, in addition to the DS and DT commonly presented in graphic novels in a manner similar to comics, Jo March's free DS (FDS) (i.e., speech with quotation marks, the introductory reporting clause removed) is found in the latest adaptation. According to Leech and Short (1982, pp. 322-323), in this presentation, Jo is seemingly talking directly to the readers without using the narrator or the translator as an intermediary. Although some confusion may be created in the readers' minds as a result of the speaker being unclear, applying this free-form approach in the adaptation speeds 
up communication. However, the lack of clear and direct symbolic modes in speech or thought representations in the Chinese adaptation (i.e., different tails pointing towards the speaker or the thinker) blurs the boundary between the speech or thought representations. This ambiguity may, to some extent, facilitate the reader's own interpretation of the meaning (Tabachnick \& Saltzman, 2015, p. 9).

\section{Discussion and conclusion}

The three adaptations correspond to what Tabachnick $(2010$, p. 25) describes as presenting the original novel in new and different ways while at the same time reaching a broader audience. Each version contextualizes Jo March using different visual and verbal resource decisions. Three adaptations of Little Women were examined using the integrated theoretical framework with Kristeva's intertextuality as the main concept combined with visual grammar (Kress \& Van Leeuwen, 1996), the synergistic model (Unsworth \& Cléirigh, 2009), and speech and thought representation (Leech \& Short, 1982). Through this specific framework, the researcher investigated the double meaning that these semiotic resources presented in the text and how they were socially and culturally situated for Taiwanese readers.

To summarize, the intertextual relationships between the original novel and each adaptation are presented differently. Specifically, the visual signs determined by the Japanese and Korean illustrators allow us to suggest that they were chosen according to their anticipated social reception in Taiwan, which places great importance on graphic narratives, as extensively discussed in Eisner (1996). However, the Chinese translations may have helped to emphasize (Unsworth \& Cléirigh, 2009, pp. 151-163) and contextualize the visual elements. Although Jo is placed in the middle of the front cover of the 2003 version, readers may be misled into believing that her mother, Mrs March, is the protagonist, given the blocking (Duncan \& Smith, 2017, p. 13) and the frequent changes in the size of the characters.

In contrast, the dull black-and-white tones and the simpler strokes together with the removal of Bunyan's allegorical play and the account Jo's success in publishing contribute to characterizing Kurasawa's Jo as a lady of only mediocre stature, talents and independence. By presenting the phonetic symbols next to each Chinese character, this adaptation seems to be targeted at very young children. In contrast, although Kim's version also omits the Bunyan play, Jo's writing gift is well presented throughout the story, and the image on the front cover could be foregrounding her success as a writer. In addition, the alternating realistic and cute portrayals have a strong appeal for readers. Nonetheless, the occasional changes to hair and eye colour may undermine the reader's identification of Jo and the other March girls.

Finally, Nev's Jo is fully presented as consistent with the original portrayal, and the image on the front cover is identical to the image in which she goes on a picnic with Laurie, which seems to reinforce her bright and optimistic side instead of her genius in writing. Importantly, the free DS and DT used by Jo was found to be employed for the first time in a graphic novel in this study. This device which serves a communicative function with an adult or more senior audience when combined with the much smaller panels. In addition, the use of onomatopoeia, notes in Kurasawa's and Kim's versions and the additional text outside the bubbles in Kim's version all reveal an awareness of the needs of their readers as well as interference from the illustrator or translator, which can be regarded as important. In this way, the illustrator or translator's ideologies are embedded in the first-person narratorial voice, which highlights its polyphonic quality, as suggested by Bakhtin (Allen, 2000, pp. 21-29).

This study's integrated theoretical framework has some weaknesses and limitations. For example, the concept of intertextuality was applied with a special focus on dialogism, as rooted in the ideas of Kristeva (1980, pp. 36-63) and contextualization in order to 
examine the ways in which these three adaptations are socially and historically contextualized. However, it is not always easy to discuss semiotic resources, especially in the case of historical contextualization. Accordingly, and similarly to a study by Green (2015, pp. 110-126), Kristeva's intertextuality serves as a main concept in this framework while simultaneously being applied in creative ways. Moreover, in order to connect Halliday's social semiotic multimodality to an investigation of both visual and verbal signs, the historical contextualization of the three adaptations is unavoidably under-emphasized in this study. Furthermore, speech or thought representation (Leech \& Short, 1982), which is often used to examine the narrator's point of view and focalization, cannot be applied in a manner consistent with the original meaning since the representation in a graphic novel, similarly to comics, lacks variation.

Nonetheless, this study is an innovative attempt to integrate three different concepts into a framework with which to explore the visual and verbal signs in the graphic novel versoins of Little Women. The use of this integrated framework enhances our understanding of how both the verbal and the visual elements of a graphic novel create meaning as well as how they elaborate, identify and extend the meaning of each element and concurrently juxtapose the narrator or translator's ideologies and communicative functions.

Indeed, the adaptations and the original work, while being separate entities, remain intertextually related. The individual adaptations per se are no doubt less significant than the artistic value and insights to be gained from investigating several adaptations alongside the original work. This new theoretical framework provides us with an opportunity to engage in interpretative pluralism in the graphic novel adaptations of Little Women. Not only does the researcher benefit from these comparisons; such comparisons also contribute substantially to the expansion of interest in multimodal texts.

\section{References}

Allen, G. (2000). Intertextuality. London: Routledge.

Appiah, K. A. (2000). Thick translation. In L. Venuti (Ed.), The translation studies reader (pp. 417-429). London: Routledge.

Barthes, R. (1977). Image-music-text. London: Fontana.

Carter, J. B. (2017). Learning from the graphic novel. In S. E. Tabachnick (Ed.), The Cambridge companion to the graphic novel (pp. 192-209). Cambridge: Cambridge University Press.

Duncan, R., \& Smith, M. J. (2017). How the graphic novel works. In S. E. Tabachnick (Ed.), The Cambridge companion to the graphic novel (pp. 8-25). Cambridge: Cambridge University Press.

Eisner, W. (1985). Comics and sequential art. Tamarac, FL: Poorhouse Press.

Eisner, W. (1996). Graphic storytelling and visual narrative. Tamarac, FL: Poorhouse Press.

Gambier, Y. (1992). Adaptation: Une ambiguïté à interroger. Meta, 37(3), 421-425.

Gannon, S. R. (1999). Getting cozy with a classic: Visualizing Little Women (1868-1995). In J. M. Alberghene \& B. L. Clark (Eds.), Little Woman and the feminist imagination: Criticism, controversy, personal essays (pp. 103-138). London: Garland.

Gardner, J., \& Herman, D. (2011). Graphic narratives and narrative theory: Introduction. SubStance, 40(1), $3-13$.

Gentzler, E. (1993). Contemporary translation theories. London: Routledge.

González, L. P. (2014). Multimodality in translation and interpreting studies: Theoretical and methodological perspectives. In S. Bermann \& C. Porter (Eds.), A companion to translation studies (pp. 119-132). London: Wiley Blackwell.

Green, M. J. A. (2015). "I don't see what good a book is without pictures or conversations": Imagery worlds and intertextuality in Alice in Wonderland and Alice in Sunderland. In S. E. Tabachnick \& E. B. Saltzman (Eds.), Drawn from the classics: Essays on graphic adaptations of literary works (pp. 110-126). Jefferson, NC: McFarland \& Company.

Groensteen, T. (2007). The system of comics. Jackson, MS: University Press of Mississippi.

Hutcheon, L. (2013). A theory of adaptation. London: Routledge. 
Jewitt, C. (2009). Different approaches to multimodality. In C. Jewitt (Ed.), The Routledge handbook of multimodal analysis (pp. 28-39). London: Routledge.

Kaindl, K. (2004). Multimodality in the translation of humour in comics. In E. Ventola, C. Cassidy, \& M. Kaltenbacher (Eds.), Perspectives on multimodality (pp. 173-192). Amsterdam: John Benjamins.

Kaindl, K. (2013). Multimodality and translation. In C. Millán \& F. Bartrina (Eds.), The Routledge handbook of translation studies (pp. 257-269). London: Routledge.

Ketola, A. (2016). Towards a multimodally oriented theory of translation: A cognitive framework for the translation of illustrated technical texts. Translation Studies, 9(1), 67-81.

Keyser, E. L. (2000). Little women: A family romance. Athens, GA: University of Georgia Press.

Kress, G., \& Van Leeuwen, T. (1996). Reading images: The grammar of visual design. London: Routledge.

Kristeva, J. (1980). Desire in language: A semiotic approach to literature and art. New York, NY: Columbia University Press.

Leech, G. N., \& Short, M. H. (1982). Style in fiction: A linguistic introduction to English fictional prose. London: Longman.

McCloud, S. (1993). Understanding comics: The invisible art. New York: Harper Perennial.

McLuhan, M. (1964). Understanding media: The extensions of man. New York, NY: Signet.

Mitchell, W. J. T. (1986). Iconology: Image, text, ideology. Chicago: University of Chicago Press.

O'Sullivan, C. (2013). Multimodality as challenge and resource for translation. Jostrans, 20, 2-14.

Oittinen, R. (2000). Translating for children. New York, NY: Garland.

Postema, B. (2013). Narrative structure in comics: Making sense of fragments. Rochester, NY: RIT Press.

Raw, L. (2013). Translation, adaptation and transformation. London: Bloomsbury.

Showalter, E. (1991). Sister's choice: Tradition and change in American women's writing. Oxford: Clarendon Press.

Tabachnick, S. E., \& Saltzman, E. B. (Eds.). (2015). Drawn from the classics: Essays on graphic adaptations of literary works. Jefferson, NC: McFarland \& Company.

Tabachnick, S. E. (2009). Teaching the graphic novel. New York, NY: MLA.

Tabachnick, S. E. (2010). The graphic novel and the age of transition: A survey and analysis. English Literature in Transition, 1880-1920, 53(1), 3-28.

Tabachnick, S. E. (2017). From comics to the graphic novel: William Horgarth to Will Eisner. In S. E. Tabachnick (Ed.), The Cambridge companion to the graphic novel (pp. 26-40). Cambridge: Cambridge University Press.

Tang, A. (2016). Narration and speech and thought presentations in comics (Unpublished doctoral thesis). University of Huddersfield, UK.

Tondro, J. (2015). Hwaet if?: Beowulf in comics. In S. E. Tabachnick \& E. B. Saltzman (Eds.), Drawn from the classics: Essays on graphic adaptations of literary works (pp. 33-45). Jefferson, NC: McFarland \& Company.

Toolan, M. J. (1988). Narrative: A critical linguistic introduction. London: Routledge.

Unsworth, L., \& Cléirigh, C. (2009). Multimodality and reading: The construction of meaning through image-text interaction. In C. Jewitt (Ed.), The Routledge handbook of multimodal analysis (pp. 151163). London: Routledge.

Vandal-Sirois, H., \& Bastin, G. L. (2013). Adaptation and appropriation: Is there a limit? In L. Raw (Ed.), Translation, adaptation and transformation (pp. 21-41). London: Bloomsbury.

Venuti, L. (2007). Adaptation, translation, critique. Journal of Visual Culture, 6(1), 25-43. 